\title{
Prostate specific antigen levels after acute myocardial infarction
}

\author{
Şerefden Açıkgöz1, Murat Can1, Sait Mesut Doğan², Görkem Mungan1, Mustafa Aydın², \\ Şerdar Kelek and Vildan Sümbüloğlu³ \\ 1Department of Biochemistry, ${ }^{2}$ Department of Cardiology, ${ }^{3}$ Department of Biostatistics, Faculty of Medicine, Zonguldak Karaelmas University, \\ Turkey
}

Prostate Specific Antigen (PSA), a member of kallikrein family, is a specific serine protease of prostatic tissue. In some case reports, changes in PSA levels after acute myocardial infarction (AMI) have been reported. In this study we evaluated variations in PSA levels post-AMI. Twenty-six male patients who had PSA levels within reference limits were included in the study. The diagnosis of AMI was confirmed by clinical findings, ECG (electrocardiogram) and cardiac marker studies. Serum total PSA (tPSA) and free PSA (fPSA) levels were measured at days 0 (day of admission), 1, 2 and 3 after AMI. PSA/ albumin ratio was also calculated in order to evaluate the effect of dilution. A statistical analysis of the results of all patients revealed significant decrease in tPSA levels and tPSA/Albumin ratio at day 2 when compared to days 0 and 3 , which showed a similar pattern. Changes of fPSA and fPSA/ Albumin ratio according to days were not found significant. In only four patients we found increased levels of tPSA and increased fPSA levels in three of them. These patients displayed severe problems such as renal failure, cardiac failure, ventricular aneurysm and cerebral ischemia due to cardiac arrest. The lower tPSA levels on day 2 suggest that tPSA can be eliminated rapidly from the circulation on days 1 and 2 , probably through the formation of complexes of tPSA with acute phase proteins.

Keywords: acute myocardial infarction, total prostate specific antigen, free prostate specific antigen

Received: 28 April, 2011; revised: 09 December, 2011; accepted: 12 December, 2011; available on-line: 20 December, 2011

\section{INTRODUCTION}

PSA (human kallikrein3, hK3) is a glandular kallikrein, primarily produced in the prostatic epithelial cells. It demonstrates a chymotrypsin-like protease activity and has no kininogenase effect (Charlesworth et al., 1999). The inactive precursor form of PSA is converted to active PSA by hK2 (Rittenhouse et al., 1998). The concentration of PSA is high in seminal fluid and it acts by degrading high molecular weight proteins terminating in liquification of semen coagulum (Osterling, 1991). The proteolytic activity of PSA is inhibited by serine protease inhibitors in the blood.

PSA is eliminated from the blood by formation of irreversible complexes with alpha1 antichymotrypsin (ACT), alpha 2 macroglobulin (A2M) and with other acute phase proteins (Otto et al., 1998). A free form of PSA is also present in the blood (Bjork et al., 1998). PSA is an important marker in prostate diseases. The serum level increases in prostate inflammatory diseases, neoplastic diseases and prostate infarction (Osterling, 1991; Bjork et al., 1998).

PSA is a member of the kallikrein-kinin system and its effects on the cardiovascular system have been reported. Decreased local kallikrein-kinin system activity can induce cardiovascular diseases (Sharma, 2006). The kallikrein-kinin system has modulatory effects in regulating smooth muscle tonus and arterial blood pressure and in preventing myocardial ischemia in the cardiovascular system (Marcondes et al., 2005). The kallikrein-kinin system has a cardioprotective role through $\beta 2$ receptor activation (Messadi et al., 2008) and $\beta 2$ receptor agonists and kallikrein have clinically positive effects on hypertension, left ventricular hypertrophy, ischemic heart disease and congestive heart failure (Sharma, 2005).

Changes in serum PSA levels are reported in certain clinical cardiac problems such as acute myocardial infarction (AMI) (Patane et al., 2010), cardiac surgery, extracorporeal cardiac by-pass (Parlaktas et al., 2006), stent implantation (Ozcan et al., 2009) and cardiopulmonary resuscitation (Koller-Strametz et al., 2000). There are some case reports investigating the changes in PSA levels after AMI (Patane \& Marte, 2009a; Patane et al., 2010). A relationship has been reported between increased PSA levels and the severity of coronary lesions and major cardiac side effects (Patane \& Marte, 2009b; Patane \& Marte, 2009c).

The aim of this study was to evaluate changes in tPSA and fPSA levels at days $0,1,2$ and 3 in 26 male AMI patients.

\section{MATERIALS AND METHODS}

After receiving permission from the Faculty Ethics Committee, 26 male patients who were being treated for AMI at Zonguldak Karaelmas University's Department of Cardiology were selected for the study. The patients gave informed consent. The diagnosis of AMI was confirmed according to the instructions of The Joint European Society of Cardiology/American College of Cardiology Committee (Antman et al., 2000). Clinical findings, ECG (electrocardiogram), cardiac enzyme and cardiac troponin I (cTNI) studies were taken into consideration. Patients who had serum tPSA and fPSA levels within the reference limits were included in the study. Blood

e-mail: serefdenacikgoz@yahoo.com

Abbreviations: ACT, alpha1 antichymotrypsin; AMI, acute myocardial infarction; $A 2 M$, alpha 2 macroglobulin; $C K M B$, creatine kinase $\mathrm{MB}$; CTNI, cardiac troponin I; PSA, prostate specific antigen; fPSA free PSA; tPSA, total PSA. 
Table 1. Summary of demographic and clinical data in study group.

mean \pm S.D. (min-max)

\begin{tabular}{ll}
\hline $\mathrm{n}$ & 26 \\
\hline Gender & 26 male \\
\hline Age, year & $60.5 \pm 10.6(32-79)$ \\
\hline Systolic pressure, $\mathrm{mmHg}$ & $135 \pm 19(170-90)$ \\
\hline Diastolic pressure, $\mathrm{mmHg}$ & $80 \pm 14(120-40)$ \\
\hline Heart rate, beats/min & $83 \pm 17(125-45)$ \\
\hline BUN & $23.69 \pm 8.69(14-55.4)$ \\
\hline Creatinine & $1.74 \pm 1.78(1-10.1)$ \\
\hline ALT & $29 \pm 15.20(9-64)$ \\
\hline AST & $69.3 \pm 63.37(16-225)$ \\
\hline GGT & $36.59 \pm 27.26(13-132)$ \\
\hline NSTEMI, $\mathrm{n}$ & 8 \\
\hline Aspirin & 4 \\
\hline Clopidogrel & 4 \\
\hline Beta blocker & 8 \\
\hline ACEI & 7 \\
\hline STEMI, $\mathrm{n}$ & 18 \\
\hline PCI & 7 \\
\hline Aspirin & 3 \\
\hline Clopidogrel & 8 \\
\hline Beta blocker & 11 \\
\hline TPA & 4 \\
\hline ACEI & 14 \\
\hline Sefence & \\
\hline
\end{tabular}

Reference values: BUN $(<23 \mathrm{mg} / \mathrm{dL})$, creatinine $(0.9-1.3 \mathrm{mg} / \mathrm{dL}), \mathrm{ALT}$ (10-49 U/L), AST (<34 U/L), GGT (<73 U/L); ACEl, angiotensin converting enzyme inhibitor; NSTEMI, non-ST elevation myocardial infarction; $\mathrm{PCl}$, percutaneus coronary intervention; STEMI, ST elevation myocardial infarction; TPA, tissue plasminogen activator.

samples taken from patients on the day of admission were accepted as day 0 and levels of PSA, fPSA, creatine kinase $\mathrm{MB}(\mathrm{CKMB})$, cardiac troponin $\mathrm{I}$ and albumin were assayed on days $0,1,2$ and 3 .

The tPSA, fPSA, CKMB, cTNI and albumin serum levels were assayed at the Department of Biochemistry. Serum tPSA and fPSA levels were assayed by using an Immulite 2000 unit (Siemens, CA, USA), CKMB and c'TNI levels by Access 2 (Beckman Coulter, CA, USA), using the chemiluminescence method, albumin and creatinine levels using the colorimetry method, blood urea nitrogen (BUN), alanine aminotransferase (ALT), aspartate aminotranferase (AST), $\gamma$-glutamyltransferase (GGT) levels using the enzymatic method were assayed with an Advia 1200 unit (Siemens, Tokyo, Japan).

Reference values were tPSA $0-4 \mathrm{ng} / \mathrm{ml}$, fPSA $<0.42$ $\mathrm{ng} / \mathrm{ml}$, CKMB 0.6-6.3 ng/ml, cTNI $<0.04 \mathrm{ng} / \mathrm{ml}$ and albumin 3.2-4.8 g/dl.

Differences in levels of tPSA, fPSA, CKMB, cTNI, albumin, tPSA/albumin ratio and $\mathrm{PPS} /$ albumin ratio at different times were recurrently analyzed with one way repeated ANOVA. The Kolmogorov-Smirnov test was used to test the normality of distributions. SPSS (version 18.0) was used in this study.

\section{RESULTS}

The ages, blood pressure values, mean pulse rates, types of myocardial infarction and treatment modalities used for our patients are summarized in Table 1.

In Table 2, zero, first, second and third day means \pm S.D. (maximum-minimum) levels of tPSA, fPSA, CKMB, cTNI and albumin levels, and the tPSA/albumin ratio and fPSA/albumin ratio are shown. Changes of the variables on different days are shown in Table 3. Variations in tPSA and fPSA levels and tPSA/albumin and fPSA/albumin ratios over time are given in Fig. 1.

CKMB and cTNI levels were higher than the reference limits. The levels decreased on days 1,2 and 3 (Table 2). Over time, the fPSA and fPSA/Albumin ratio did not show a significant difference $(p=0.479, p=0.371)$, and average fPSA values for the days were within reference limits. The levels of tPSA were significantly lower on day 1 than on day $0(p=0.012)$. The tPSA levels and tPSA/Albumin ratios were significantly lower on day 2 than day $0 \quad(p=0.043, p=0.043)$. However, the decrease between day 1 and day 2 was not significant $(p=0.347$, $p=0.270)$. On day 3, a significant increase compared to day 2 was evident $(p=0.014, p=0.031)$ and the level returned to that of day 0 . The average values of tPSA and albumin for each day were within reference limits.

We found increases of tPSA in four of our patients and increases of fPSA levels in three of them, albeit all these values were within reference limits. These patients displayed severe problems such as renal failure, cardiac failure, ventricular aneurysm and cerebral ischemia due to cardiac arrest.

\section{DISCUSSION}

PSA is a serine protease that shows chymotripsinlike proteolytic activity and no kinin generating activity

Table 2. tPSA, fPSA, CKMB, CTNI and albumin levels, and tPSA/albumin ratio and fPSA/albumin ratios (mean \pm S.D.) (min-max) after AMI (days $0,1,2$ and 3).

\begin{tabular}{lllll}
\hline AMI & Day 0 & Day 1 & Day 2 & Day 3 \\
\hline tPSA $(\mathrm{ng} / \mathrm{mL})$ & $1.088 \pm 1.034(0.092-3.320)$ & $0.913 \pm 0.817(0.084-2.890)$ & $0.825 \pm 0.685(0.082-2.490)$ & $1.106 \pm 1.052(0.072-3.450)$ \\
fPSA $(\mathrm{ng} / \mathrm{mL})$ & $0.322 \pm 0.210(0.085-0.802)$ & $0.286 \pm 0.104(0.094-0.488)$ & $0.328 \pm 0.222(0.095-0.858)$ & $0.295 \pm 0.236(0.075-0.858)$ \\
CKMB $(\mathrm{ng} / \mathrm{mL})$ & $131.2 \pm 118.3(2.4-305.0)$ & $63.0 \pm 85.3(2.8-304.0)$ & $19.1 \pm 21.8(1.2-90.2)$ & $6.6 \pm 5.3(0.8-19.5)$ \\
cTNI $(\mathrm{ng} / \mathrm{mL})$ & $33.38 \pm 38.10(0.17-116.7)$ & $23.46 \pm 27.11(0.14-100.0)$ & $16.30 \pm 21.21(0.05-97.10)$ & $10.91 \pm 9.99(0.03-35.80)$ \\
Albumin (gr/dL) & $4.19 \pm 0.33(3.3-4.6)$ & $3.89 \pm 0.47(3.0-5.0)$ & $3.89 \pm 0.46(2.7-4.6)$ & $3.80 \pm 0.44(2.9-4.7)$ \\
tPSA/Albumin & $0.301 \pm 0.287(0.026-0.810)$ & $0.257 \pm 0.245(0.023-0.756)$ & $0.212 \pm 0.172(0.025-0.530)$ & $0.315 \pm 0.307(0.024-1.145)$ \\
fPSA/Albumin & $0.090 \pm 0.0480 .023-0.169)$ & $0.080 \pm 0.026(0.025-0.119)$ & $0.109 \pm 0.086(0.034-0.318)$ & $0.104 \pm 0.086(0.027-0.296)$ \\
\hline
\end{tabular}


Table 3. Daily changes in tPSA, fPSA, CKMB, cTNI levels, and tPSA/Albumin and fPSA/Albumin ratios after AMI.

\begin{tabular}{|c|c|c|c|c|c|c|c|}
\hline AMI & tPSA (ng/mL) & fPSA $(n g / m L)$ & $\begin{array}{l}\text { CKMB } \\
\text { (ng/mL) }\end{array}$ & cTNI (ng/mL) & $\begin{array}{l}\text { Albumin } \\
\text { (g/dL) }\end{array}$ & tPSA/albumin & fPSA/albumin \\
\hline Changes overtime & $p=0.018$ & $p=0.479$ & $P<0.001$ & $p=0.005$ & $P<0.001$ & $p=0.043$ & $P=0.371$ \\
\hline 0-1 day & $p=0.012$ & & $P=0.005$ & $p=0.166$ & $P=0.003$ & $P=0.060$ & \\
\hline 0-2 day & $p=0.043$ & & $P<0.001$ & $p=0.032$ & $P=0.003$ & $P=0.043$ & \\
\hline 1-2 day & $p=0.347$ & & $P=0.004$ & $p=0.025$ & $P=0.958$ & $P=0.270$ & \\
\hline 2-3 day & $p=0.014$ & & $P=0.004$ & $p=0.012$ & $P=0.226$ & $P=0.031$ & \\
\hline $0-3$ day & $p=0.831$ & & $P<0.001$ & $p=0.004$ & $P<0.001$ & $P=0.613$ & \\
\hline
\end{tabular}

(Charlesworth et al., 1999). Its proteolytic activity is inhibited by serum protease inhibitors in the blood. This inhibition occurs by the creation of irreversible complexes with ACT, A2M and with other acute phase proteins (Otto et al., 1998, Birkenmeier et al., 1999). Moreover, PSA's free form exists in the blood (Bjork et al., 1998).

Parlaktas et al. (2006) found increased levels of tPSA on the 1 st and 5 th days after coronary artery bypass surgery in patients with extracorporeal circulation used during surgery. Coker et al. (1997) measured tPSA levels at 6-hour intervals after coronary artery bypass surgery with extracorporeal circulation for 48 hours, and they reported increased tPSA levels. The two papers indicated

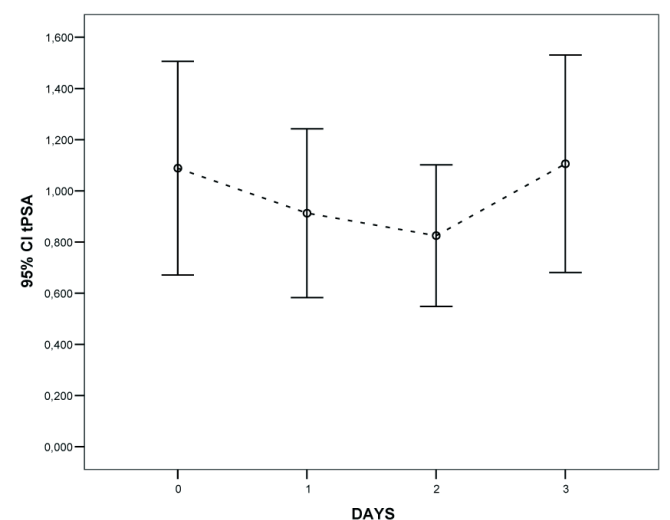

$\operatorname{tPSA}(\mathrm{ng} / \mathrm{mL})$

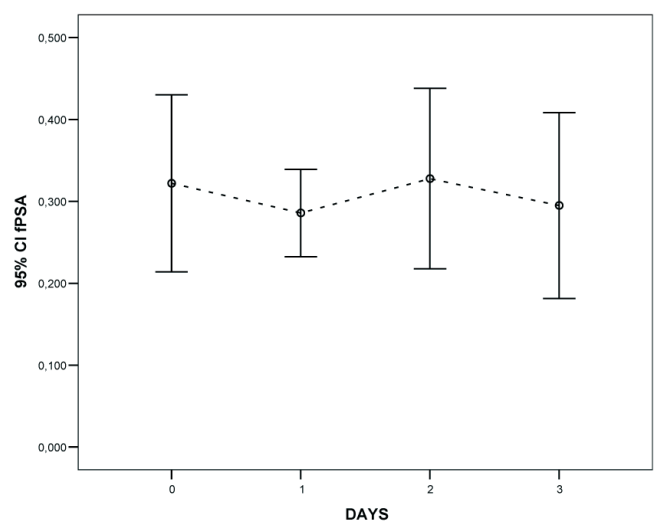

fPSA $(\mathrm{ng} / \mathrm{mL})$ ischemia as the casual factor (Parlaktas et al., 2006; Coker et al., 1997). During coronary artery bypass surgery, several authors (Parlaktas et al., 2006; Coker et al., 1997) have attributed high tPSA values to the hypotensive shock which may occur during clamping the aorta, causing pelvic ischemia and later causing prostate ischemia and/or infarction. In contrast to those studies, we found decreased tPSA values that were probably not associated with the prostate ischemia caused by pelvic ischemia and/or infarction in patients with AMI, because of the absence of aortic clamping in our study. Twelve and 24 hours after cardiopulmonary resuscitation, KollerStrametz et al. (2000) noted elevated tPSA levels and these lowered in a stepwise fashion during a 7-day pe-

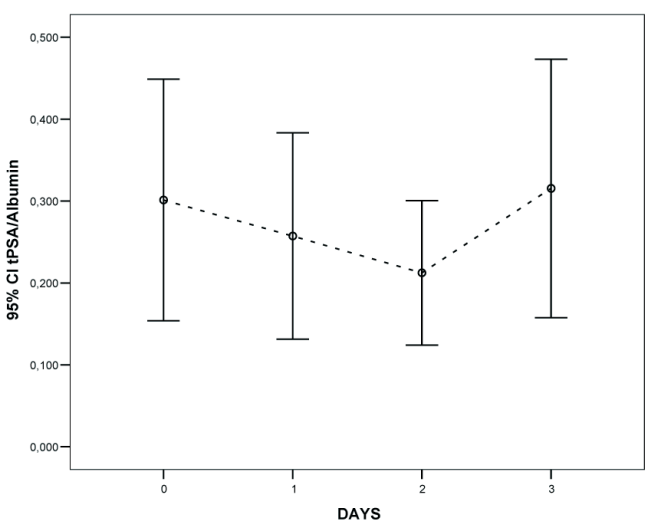

tPSA/Albumin ratio

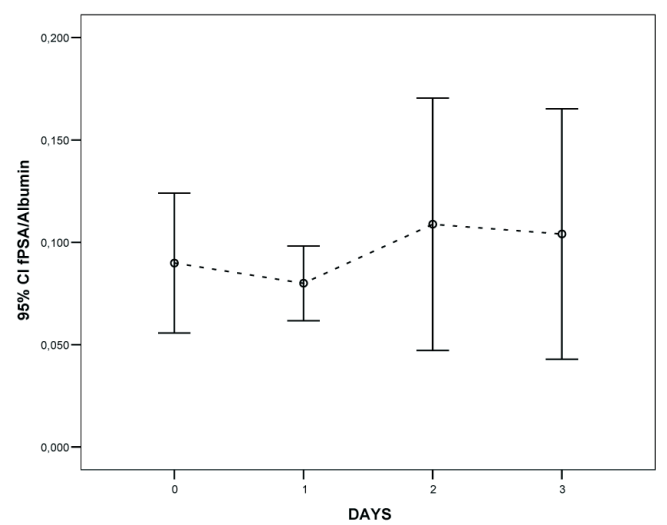

fPSA/Albumin ratio

Figure 1. Variations in TPSA and fPSA levels, tPSA/albumin and fPSA/albumin ratios over time. 
riod. Berent et al. (2006) found increased tPSA levels 6, 12 and 48 hours after prolonged cardiopulmonary resuscitation and they suspected ischemia (Koller-Strametz et al., 2000; Berent et al., 2006).

Özcan et al. (2009) found increased levels of tPSA and fPSA levels in patients who had received coronary artery stenting. They found these increases at the 24th hour and lowering to baseline values at day 30. The changes between those days remain obscure. They explained their results with the findings of Koller-Strametz et al. (2000) and Patane et al. (2009b). Unfortunately, in the case reports of Patane et al. (2010) there were both increases and decreases of tPSA and fPSA after AMI (Patane \& Marte, 2009a; Patane et al., 2009; Patan \& Marte 2010). Patane et al. (2009a) reported that tPSA decreased in three patients with AMI. In these patients fPSA increased in one and decreased in two (the patients did not have significant coronary artery stenosis) (Patane \& Marte, 2009a). In another report, tPSA and fPSA increased in a patient with significant coronary artery disease and coronary artery aneurysm (Patane et al., 2010). Patane et al. (2009) reported a patient with AMI and atrial fibrillation who had elevated tPSA and fPSA levels. They reported a rise in tPSA level in another patient who had AMI and paroxysmal ventricular tachycardia, paroxysmal atrial fibrillation associated with subclinical hyperthyroidism and chronic renal failure (Patane \& Marte, 2010)

In our patients with increases in tPSA or fPSA, there was no stent application. However, they had severe problems such as renal failure, cardiac failure, right ventricular aneurysm, and brain ischemia due to cardiac arrest. In one of these patients NSTEMI (non-ST elevation myocardial infarction), in three STEMI (ST elevation myocardial infarction) was found.

The rise of tPSA in our four patients did not change the statistical result. In our study when all of our patients' findings were statistically examined we found similar results as did Crook et al. (1997).

Crook et al. (1997) measured tPSA levels 1, 2 and 3 days after AMI and reported tPSA levels significantly lower on the second day than on the first and third days. In that study as well as in our study, the maximum reduction was on day 2 and a significant increase was detected on day 3. However, they did not determine fPSA levels in these patients nor do they state the number of their patients. They indicated that their results could be associated with factors such as thrombolytic therapy, reduced physical activity and acute phase response (Crook et al., 1997).

According to Birkenmeier et al. (1999) PSA forms complexes such as PSA-A2M and PSA-ACT in the blood. These complexes are removed from the blood by binding to the Alpha 2 macroglobuline/LDL receptor related protein (A2M/LRP) in the liver (Otto et al., 1998; Birkenmeier et al., 1999). Bjork et al. (1998) showed that fPSA is mainly eliminated by glomerular filtration. In our study, the fPSA level decreased on day 1 and returned to the level of day 0 on day 2 but these changes were not significant. This result may be due to the different forms of PSA having been eliminated at different rates and by different organs.

In our study, despite the continuing of the therapy for AMI, the decreases of tPSA on the first and second days and an increase on the third day towards day 0 levels may be attributable to a factor other than the therapy. In that respect, PSA may develop a complex with acute phase proteins which have antiprotease effects and therefore they may be eliminated from the circulation more rapidly. The tPSA levels and tPSA/albumin ratio showed a similar pattern, with a decrease in both on day 2 indicating that the decrease of tPSA was not dilutional.

These results give us the impression that the second day lowering of tPSA in AMI is mostly related to the responses of acute phase proteins forming complexes with tPSA. A gene polymorphism of the receptors for the clearance of PSA-ACT complexes may play some role in the individual variations of PSA alterations. Further studies are needed to investigate this possibility.

\section{Acknowledgement}

The authors thank Gregory T. Sullivan of Ondokuz Mayis Universty in Samsun, Turkey for editing the English in an earlier version of this manuscript.

\section{REFERENCES}

Antman E, Bassand J-P, Klein W, Ohman M, Sendon JLL, Ryden L et al. (2000) The Joint European Society of Cardiology/American College of Cardiology Committee.

Myocardial Infarction Redefined - A Consensus Document of The Joint European Society of Cardiology/American College of Cardiology Committee for the Redefinition of Myocardial Infarction. (2000) J Am Coll Cardiol 36: 959-969.

Berent R, Auer J, Porodko M, Lamm G, Weber T, Wimmer E et al. (2006) Influence of cardiopulmonary resuscitation on levels of tumour markers. Eur J Cancer Care 15: 252-256.

Birkenmeier G, Struck F, Gebhardt R (1999) Clearance mechanism of prostate specific antigen and its complexes w1th $\alpha 2$-macroglobulin and $\alpha 1$-antichymotrypsin. J Urol 162: 897-901.

Bjork T, Ljungberg B, Pironen T, Abrahamsson PA, Pettersson K, Abraham T et al. (1998) Rapid exponential elimination of free prostate specific antigen contrasts the slow, capacity limited elmination of PSA complexed to alpha1-antichymotrypsin from serum. Urology 51: $57-62$.

Charlesworth MC, Young CY, Miller VM, Tindall DJ (1999) Kininogenase activity of prostate derived human glandular kallikrein (hk2) purified from seminal fluid. I Androl 20: 220-229.

Coker C, Sherwood RA, Cravford T, Saadeh F, Mulvin D, Brakenbury E et al. (1997) Ischemic damage to the prostate during cardiac surgery: A clinical model. The Prostate 32: 85-88.

Crook M, Preston K, Lancaster I (1997) Serum prostatic-antigen concentrations in acute myocardial infarction (Letter). Clin Chem 43: 1670.

Koller-Strametz J, Fritzer M, Gwechenberger M, Geppert A, Heinz G, Haumer M et al. (2000) Elevation of prostate-specific markers after cardiopulmonary resuscitation. Circulation 102: 290-293.

Marcondes S, Antunes E (2005) The plasma and tissue kininogenkallikrein-kinin system: role in the cardiovascular system. Curr Med Chem-Cardiovasc Hematol Agents 3: 33-34.

Messadi-Laribi E, Griol-Charhbili G, Gaies E, Vincent MP, Heudes D, Meneton P et al. (2008) Cardioprotection and kallikrein-kinin system in acute myocardial ischemia in mice. Clin Exp Pharmacol Physiol 35: 489-493.

Oesterling JE (1991) Prostate Specific Antigen: A critical assessment of the most useful tumor marker for adenocarcinoma of the prostate (Abstract). J Urol 145: 907-923.

Otto A, Bar J, Birkenmeier G (1998) Prostate-specific antigen forms complexes with human alpha 2 macroglobulin receptor/LDL receptor related protein. I Urol 159: 297-303.

Ozcan T, Bozlu M, Muslu N, Gozukara KH, Seyis S, Akcay B (2009) Elevation of the serum total and free prostate specific antigen levels after stent implantation in patients with coronary artery disease. Swiss Med Wkly 139: 672-675.

Parlaktas BS, Naseri E, Uluocak N, Elalmış AO, Erdemir F, Etikan I (2006) Comparison of the effects of on-pump versus off-pump coronary artery bypass surgery on serum prostate-specific antigen levels. Int J Urol 13: 234-237.

Patane S, Marte F (2009a) Prostate specific antigen and acute myocardial infarction: A possible new intriguing scenario. Int J Cardiol 134: 147-149.

Patane S, Marte F (2009b) Prostate-specific antigen kallikrein: from prostate cancer to cardiovascular system. Eur Heart J 30: 1169-1170.

Patane S, Marte F (2010) Paroxysmal ventricular tachycardia and paroxysmal atrial fibrillation associated with subclinical hyperthyroidism, chronic renal failure and elevation of prostate-specific antigen during acute myocardial infarction (Letter). Int J Cardiol 138: 44-46. 
Patane S, Marte F (2011) Prostate-specific antigen kallikrein and acute myocardial infarction: Where we are. Where are we going? Int J Cardiol 146: 20-22.

Patane S, Marte F, Bella GD, Ciccarello G (2009) Changing axis deviation, paroxysmal atrial fibrillation and elevation of prostate-specific antigen during acute myocardial infarction. (Letter). Int JCardiol 137: $37-40$.

Patane S, Marte F, Sturiale M, Grassi R, Patane F (2010) Significant coronary artery disease associated with coronary artery aneurysm and elevation of prostate-specific antigen during acute myocardial infarction (Letter). Int J Cardiol 141: 39-42.
Rittenhouse HG, Finlay JA, Mikolajczyk SD, Partin AW (1998) Human kallikrein 2 (hk2) and prostate specific antigen (PSA): two closely related, but distinct, kallikreins in the prostate. (Abstract). Crit Rev Clin Lab Sci 35: 275-368.

Sharma JN (2006) Role of tissue kallikrein-kininogen-kinin pathways in the cardiovascular system. Arch Med Res 37: 299-306.

Sharma JN (2005) The Kallikrein-Kinin System: from mediator of inflammation to modulator of cardioprotection. Inflammopharmacology 12: $591-596$ 
